\title{
Development and validation of a screening model for diabetes mellitus in patients with periodontitis in dental settings
}

\author{
Naichuan Su ${ }^{1} \cdot$ Wijnand J. Teeuw ${ }^{2} \cdot$ Bruno G. Loos ${ }^{2} \cdot$ Madeline X. F. Kosho $^{2} \cdot$ Geert J. M. G. van der Heijden ${ }^{1}$
}

Received: 9 January 2020 / Accepted: 8 April 2020 / Published online: 15 June 2020

(C) The Author(s) 2020

\begin{abstract}
Objectives To identify predictors in patient profiles and to develop, internally validate, and calibrate a screening model for diabetes mellitus (DM) in patients with periodontitis in dental settings

Materials and methods The study included 204 adult patients with periodontitis. Patients' socio-demographic characteristics, general health status, and periodontal status were recorded as potential predictors. The diabetic status was considered the outcome, classified into no DM, prediabetes (pre-DM), or DM. Multinomial logistic regression analysis was used to develop the model. The performance and clinical values of the model were determined.

Results Seventeen percent and $47 \%$ of patients were diagnosed with DM and pre-DM, respectively. Patients' age, BMI, European background, cholesterol levels, previous periodontal treatment, percentage of the number of teeth with mobility, and with gingival recession were significantly associated with the diabetic status of the patients. The model showed a reasonable calibration and moderate to good discrimination with area under the curve (AUC) values of 0.67 to 0.80 . The added predictive values for ruling in the risk of DM and pre-DM were 0.42 and 0.11 , respectively, and those for ruling it out were 0.05 and 0.17 , respectively.

Conclusions Predictors in patient profiles for screening of DM and pre-DM in patients with periodontitis were identified. The calibration, discrimination, and clinical values of the model were acceptable.

Clinical relevance The model may well assist clinicians in screening of diabetic status of patients with periodontitis. The model can be used as a reliable screening tool for DM and pre-DM in patients with periodontitis in dental settings.
\end{abstract}

Keywords Periodontitis $\cdot$ Diabetes mellitus $\cdot$ Screening $\cdot$ Predictors

Clinical trial registration The dataset used for this manuscript is based on an observational (non-randomized and non-treatment) design. The outcomes of the observational design have been published previously (see Teeuw et al., 2017). The study has been given ethical clearance (2013.343) from the Medical Ethics Review Committee of VU University Medical Center Amsterdam (VUmc), and the PI of this study decided not to register the project since it does not involve randomization of treatment. The study data not being registered in a trial register invalidates neither the initial observational study as published nor the current manuscript. That is, for the current manuscript, the dataset of the already published observational design is used for other purposes, being predictive diagnostic modeling.

Electronic supplementary material The online version of this article (https://doi.org/10.1007/s00784-020-03281-w) contains supplementary material, which is available to authorized users.

Naichuan $\mathrm{Su}$

n.su@acta.nl

1 Department of Social Dentistry, Academic Centre for Dentistry Amsterdam (ACTA), University of Amsterdam and Vrije Universiteit Amsterdam, Amsterdam, the Netherlands
2 Department of Periodontology, Academic Centre for Dentistry Amsterdam (ACTA), University of Amsterdam and Vrije Universiteit Amsterdam, Amsterdam, the Netherlands 


\section{Introduction}

Periodontitis is a common chronic inflammatory disease that is characterized by the destruction of the supporting structures of the teeth [1]. Based on the Global Burden of Disease (GBD) study 2010, chronic periodontitis is the second most common disease in dentistry with a prevalence of $10.8 \%$ in the global population [2]. Diabetes mellitus (DM) is a heterogeneous group of physiological disorders characterized by hyperglycemia resulting directly from insulin resistance, inadequate insulin secretion, or excessive glucagon secretion [3]. It is reported that there were 382 million people worldwide that have DM in 2013, and the number of people with DM by 2035 is expected to rise to 592 million [4].

There is a strong association between periodontitis and DM. DM has been unequivocally confirmed as a major risk factor for periodontitis [5-8]. It is reported that DM can (i) directly change the subgingival periodontal flora due to the increased glucose level in crevicular fluid and blood, (ii) exaggerate the inflammatory host response by producing more inflammatory mediators and inflammatory cytokines in gingival crevicular fluid and gingival tissue, (iii) impair production of bone matrix component, (iv) change the permeability of gingival capillaries, and (v) impair wound healing $[8,9]$. Therefore, the reduction in defense mechanisms and the increased susceptibility to infection in patients with DM severely exacerbate the onset, progression, and severity of periodontitis [9]. Based on a meta-analysis including 49,262 individuals, DM increased the risk of incidence or progression of periodontitis by $86 \%$ [10]. However, the association between periodontitis and prediabetes (pre-DM) is controversial [11-14].

The consensus has been reached among all the key stakeholders relating to dental teams, including patients, dentists, dental hygienists, dental students, and physicians that the engagement of the dental workforce to identify DM or pre-DM was beneficial [15]. Early screening of DM or pre-DM for patients with periodontitis may guide clinicians to develop different dental treatment strategies for the patients, such as the adjunctive systemic antibiotic use in scaling, root planing, or periodontal surgery $[16,17]$. Also, early screening of DM or pre-DM may help reduce patients' comorbidities and mortality, thus improving patients' health outcomes [18]. There is growing evidence showing that periodontal treatment leads to an improvement of glycemic control of patients with DM and pre-DM [19-21]. A screening of DM or pre-DM is also an important reminder that the patients need to start with systematic and comprehensive periodontal check-ups or treatment. While DM may remain undetected for some period, around 1 in every 3 people who have DM are not aware of their status $[22,23]$. Besides, the prevalence of undiagnosed pre-DM in Korean young adults aged $<40$ years was reported to be up to $25 \%$ [24]. Therefore, in the decision-making on treatment strategies, it is highly advisable for dentists to verify whether patients with periodontitis suffer from DM or pre-DM at the chairside.

While the use of the glucose meter and finger stick testing has been recommended for dental practices, only a few dental offices own and use a glucose meter [25]. This may be because dentists consider glucose testing out of scope for their daily practice $[22,25]$, and these recommended tests are invasive. Therefore, the development of a clinical screening model for DM and pre-DM based on patients' profiles might be of great clinical value in daily practice. Such a clinical screening model should be easy-to-use and acceptable for the clinicians and patients with periodontitis in daily practice.

Therefore, the aims of the present study were to (1) identify potential predictors in patient profiles that allow accurate screening of DM and pre-DM; and (2) develop, internally validate, and calibrate a screening model for DM and preDM in patients with periodontitis in dental settings.

\section{Materials and methods}

\section{Participants}

The study was designed as a cross-sectional study. The study involved 204 consecutive patients with periodontitis who were referred to the Department of Periodontology of the Academic Centre for Dentistry Amsterdam (ACTA) for the diagnosis and treatment of periodontitis between February 2014 and September 2015, as previously described by Teeuw et al. 2017 [22]. Patients referred to ACTA for their periodontitis were recruited during their first visit to the periodontal clinic. The inclusion criteria for the patients were: (1) patients were diagnosed with periodontitis based on the Centers for Disease Control and Prevention-American Academy of Periodontology (CDC-AAP) case definition; (2) patients were over 18 years age; and (3) patients provided their informed consent.

The study has been approved by the Medical Ethics Review Committee of the VU University Medical Center Amsterdam (VUmc) (2013.343) and has been performed in accordance with the ethical standards as laid down in the 1964 Declaration of Helsinki and its later amendments or comparable ethical standards.

\section{Potential predictors}

Potential predictors included patient socio-demographic characteristics (age, gender, highest completed education level, and European background), self-reported lifestyle and general health status (smoking, hypertension, hypercholesterolemia, family diabetes, body mass index (BMI)), and periodontal health status (severity of periodontitis, number of teeth, 
percentage of the number of teeth with $\geq 50 \%$ bone loss, percentage of the number of teeth with probing pocket depth (PPD) $\geq 6 \mathrm{~mm}$, percentage of the number of teeth with mobility, percentage of the number of teeth with gingival recession, bleeding index, and previous periodontal treatment). These potential predictors were identified a priori based on the previous literature and periodontal experts' knowledge and experience. The details on the definition and measurement of the predictors are shown in Online Resource 1.

\section{Outcome}

The outcome of the study was diabetic status, which was assessed with $\mathrm{HbAlc}$ values based on finger-stick test. The details for the finger-stick procedures adopted in the study were presented in Teeuw et al. 2017 [22]. DM status was classified into three categories including "no DM," "preDM," and "DM" based on the American Diabetes Association (ADA) guidelines [26]. No DM was defined as the $\mathrm{HbA} 1 \mathrm{c}$ values $<39 \mathrm{mmol} / \mathrm{mol}$. Pre-DM was defined as the $\mathrm{HbAlc}$ values of $39-47 \mathrm{mmol} / \mathrm{mol}$. DM was defined as the $\mathrm{HbAlc}$ values $\geq 48 \mathrm{mmol} / \mathrm{mol}$.

\section{Statistical analysis}

Screening of potential predictors and modeling First, collinearity tests of the potential predictors were performed with Spearman rank correlation tests. If the correlation coefficients between two predictors were larger than 0.9 , one of the two predictors was excluded from the modeling procedures. The bivariate association of each predictor with the three-category outcome (no DM, pre-DM, and DM) was tested by using the chi-square test for categorical predictors and Kruskal-Wallis test for continuous predictors. Predictors with a bivariate $P$ value $\leq 0.25$ were selected for inclusion in the subsequent modeling procedure. Multivariable multinomial logistic regression analysis with backward-selection procedures $(P>$ 0.25 for removal) was then used for modeling. A less stringent threshold of 0.25 was used in both the bivariate tests, and the multivariable regression analyses in selection and exclusion of potential predictors because this could avoid false negative findings in both modeling stages and avoid unjustified exclusion of predictors from the final model, especially when the sample size is small [27].

Shrinkage factor To improve the internal validity of the model, the regression coefficients of the predictors in the model were multiplied by a shrinkage factor. A shrinkage factor ranges from 0 to 1 . The shrinkage factor of the model was calculated as (modelX $\left.{ }^{2}-d f\right) /$ modelX $^{2}$, where model $\mathrm{X}^{2}$ indicates the likelihood ratio of the fitted model, and $d f$ indicates the degrees of freedom of the number of candidate predictors considered for the model $[28,29]$.
Calibration Calibration is defined as the agreement between the predicted outcomes and observed outcomes [30]. Calibration of the model was assessed by plotting the predicted individual probabilities against the observed actual probabilities for each outcome category and by the Pearson goodness-of-fit statistic. If the $P$ value of the Pearson goodness-of-fit statistic test is $>0.05$, it indicates no or low evidence for lack of fit of the model [31].

Discrimination Discrimination is defined as the ability of a model to differentiate between those with and those without the outcome event [30]. Discrimination of the model was assessed with polytomous discrimination index (PDI) [32] and area under the receiver operating characteristic curve (AUC) [28]. The PDI, which ranges from 0 to 1 , is interpreted as the probability of a multinomial model to correctly identify a case from a randomly selected category within a set of $\mathrm{K}$ cases ( $\mathrm{K}$ is the number of categories of a multinomial outcome) [32]. Discrimination of the model was also assessed with two AUCs, relating no DM to the other two outcome categories (DM and pre-DM) in each receiver operating characteristic curve (ROC) area [28].

Clinical values Clinical added values of the model were assessed using the prevalence (prior probability) and posterior probabilities of the outcome categories. The posterior probability was defined as positive predictive values (PPVs) and negative predictive values (NPVs). PPV was defined as the proportions of presence of pre-DM or DM based on the model in patients with pre-DM or DM. NPV was defined as the proportions of absence of pre-DM or DM based on the model in patients with no pre-DM or DM. The PPVs and the prevalence of pre-DM and DM were used to assess the added value of the model for ruling in the risk of pre-DM and DM, while the NPVs and the complement of the prevalence of pre-DM and DM were used to assess the added values of the model for ruling out the risk of pre-DM and DM.

Scoring system A clinical prediction rule for the diabetic status of the patients was developed to provide an estimate for individual patients of their absolute risk of having no DM, preDM, and DM. No DM was regarded as the reference category of the outcome, so the predicted probabilities of pre-DM and DM in individual patients were calculated as below [28]:

$$
P_{\text {preDM }}=\frac{\exp (\text { LPpreDM })}{1+\exp (\text { LPpreDM })+\exp (\text { LPDM })} ;
$$

$P_{\mathrm{DM}}=\frac{\exp (\text { LPDM })}{1+\exp (\text { LPpreDM })+\exp (\text { LPDM })}$.

where LPpreDM $=$ linear predictor of pre-DM $=\beta 0_{\text {preDM }}$ $+\beta 1_{\text {preDM }} X_{1}+\ldots+\beta \mathrm{i}_{\text {preDM }} X_{\mathrm{i}}$; and LPDM $=$ linear predictor 
of $\mathrm{DM}=\beta 0_{\mathrm{DM}}+\beta 1_{\mathrm{DM}} \mathrm{X}_{1}+\ldots+\beta \mathrm{i}_{\mathrm{DM}} X_{i} . \beta$ represents the regression coefficient of a predictor in the model. The status of a patient for any binary variable can be expressed as either 0 or 1 , while the status of a patient for any continuous variable can be expressed as its numeric value. As the sum of the predicted probabilities of each outcome category in the model is 1 , the probability of patients with no DM can be calculated as $1-\mathrm{P}_{\text {preDM }}-\mathrm{P}_{\mathrm{DM}}$. Patients were allocated to the outcome category with the highest predicted probability.

To facilitate the calculation of the probabilities of no DM, pre-DM, and DM in individual patients separately, the multinomial regression model was converted to a score chart. The score of each included predictor in the score chart was produced by the shrunken regression coefficients being divided by the smallest regression coefficient of the predictors and subsequently rounded. Line charts were then developed to help determine the predicted probability of no DM, pre-DM, and DM.

All the statistical procedures mentioned above were performed with SPSS software 25.0 (IBM, New York, the USA) and R software 3.2.3 (R Development Core Team, Vienna, Austria). The discrimination, calibration, added values, and scoring system of the model were all assessed based on the shrunken regression coefficients. Completecase analysis was used for the missing data of the study.

\section{Results}

A total of 204 patients with periodontitis (98 males and 106 females) were enrolled in the study. Their diabetic status was unknown at study inclusion. The mean age \pm standard deviation (SD) of the patients was $50.9 \pm 10.9$ years. The mean age \pm SD of male patients was $50.9 \pm 10.5$ years while that of female patients was $50.8 \pm 11.4$ years. Based on their HbAlc values, 35 patients (17\%) were classified with DM and 95 patients (47\%) with pre-DM.

The correlation coefficients between any two of the potential predictors were smaller than 0.9. The distribution of potential predictors based on the three-category outcome is presented in Table 1. A total of 13 predictors had a $P$ value of $\leq$ 0.25 and were selected for possible inclusion in the multivariate multinomial logistic regression analyses using the backward-selection procedure.

In the multivariate modeling, 201 patients were included, while three patients were excluded because of a missing data of one or more predictors in the multivariable model. The predictors included in the final model based on the multivariate multinomial logistic regression analysis are presented in Table 2. When patients with no DM were regarded as the reference, patients with older age, higher BMI, the absence of previous periodontal treatment, non-European background, and presence of hypercholesterolemia were more likely to have pre-DM, while patients with higher BMI, higher percentage of teeth with mobility, higher percentage of teeth with gingival recession, the absence of previous periodontal treatment, non-European background, and presence of hypercholesterolemia were more likely to have DM.

The shrinkage factor was 0.78 . Figure 1 shows the calibration plot of the model. The three curves in the model were all lying close to the diagonal line, which indicated that there was a good fit between the predicted probability and actual probability of the three types of diabetic status of patients with periodontitis. With a resulting $P$ value for the Pearson goodness-of-fit test of 0.32 , the model was also shown to be a good fit. The PDI of the multinomial model was 0.61 . The AUC values for pre-DM and DM were 0.67 (95\%CI, 0.60, $0.75)$ and $0.80(95 \% \mathrm{CI}, 0.72,0.88)$ (Fig. 2). It showed that the general discrimination of the model was moderate to good.

Table 3 presents the clinical values of the model, in aspects of prevalence, sensitivity, specificity, PPV, and NPV. When DM was considered the predicted outcome category, the added value of the model for ruling in the risk of DM was $0.42(95 \% \mathrm{CI}, 0.20,0.63)$ in addition to the prevalence, while that for ruling out the risk of DM was $0.05(95 \% \mathrm{CI},-0.02$ 0.12 ) in addition to the compliment of the prevalence. When pre-DM was considered the predicted outcome category, the added value of the model for ruling in the risk of pre-DM was $0.11(95 \% \mathrm{CI}, 0.00,0.22)$ in addition to the prevalence, while that for ruling out the risk of pre-DM was $0.17(95 \% \mathrm{CI}, 0.05$, 0.29 ) in addition to the compliment of prevalence.

To enhance the clinical usefulness of the model, the final multinomial regression model was transformed into a score chart based on the shrunken regression coefficients (Table 4). A clinician can easily calculate the sum scores for pre-DM and DM of individual patients separately based on the predictors in the score chart. Then, a clinician can determine the corresponding predicted probability of pre-DM and DM based on the sum scores for pre-DM and DM by using the line charts (Fig. 3). The predicted probability of no DM can be calculated by 1 minus the predicted probability of pre-DM minus the predicted probability of DM.

For example, a patient with periodontitis came to the clinic to seek treatment. He was a European and 50 years old. His self-reported BMI was 25 . He had hypercholesterolemia and received no previous periodontal treatment. He had a total of 24 remaining teeth, while 12 teeth were mobile, and 20 teeth had gingival recession. Therefore, based on the score chart (Table 4), the patient had a sum score for pre-DM of 517 and a sum score for DM of 980 . Then, based on the line charts (Fig. 3), the predicted probability for pre-DM can be estimated to be around $52 \%$ and that for DM around $28 \%$. The predicted probability for no DM can be calculated as 1 $-52 \%-28 \%=20 \%$. Therefore, the patient was very likely to have a pre-DM because the predicted probability for preDM was the highest. 
Table 1 Distribution of the potential predictors based on the diabetic status of patients with periodontitis $(N=204)$

\begin{tabular}{|c|c|c|c|c|c|c|}
\hline Predictors & $\begin{array}{l}\text { Description of } \\
\text { coding }\end{array}$ & Values & No DM & Pre-DM & $\mathrm{DM}$ & $\begin{array}{l}P \\
\text { value }^{\mathrm{g}}\end{array}$ \\
\hline \multicolumn{7}{|l|}{ Socio-demographic characteristics } \\
\hline Age & Continuous & $\begin{array}{l}50.9 \pm 10.9 \\
(N=204)\end{array}$ & $\begin{array}{l}47.6 \pm 11.7 \\
(N=74)\end{array}$ & $\begin{array}{l}53.6 \pm 9.6 \\
(N=95)\end{array}$ & $\begin{array}{l}50.4 \pm 11.2 \\
(N=35)\end{array}$ & $<0.01$ \\
\hline Gender & $\begin{array}{l}\text { Male } \\
\text { Female }\end{array}$ & $\begin{array}{l}98 \\
106\end{array}$ & $\begin{array}{l}34 \\
40\end{array}$ & $\begin{array}{l}45 \\
50\end{array}$ & 19 & 0.71 \\
\hline Highest completed education level & $\begin{array}{l}\text { Low } \\
\text { Medium } \\
\text { High }\end{array}$ & $\begin{array}{l}49 \\
74 \\
81\end{array}$ & $\begin{array}{l}14 \\
27 \\
33\end{array}$ & $\begin{array}{l}20 \\
36 \\
39\end{array}$ & $\begin{array}{l}15 \\
11 \\
9\end{array}$ & 0.07 \\
\hline European background & $\begin{array}{l}\text { European } \\
\text { Non-European }\end{array}$ & $\begin{array}{l}147 \\
57\end{array}$ & $\begin{array}{l}60 \\
14\end{array}$ & $\begin{array}{l}69 \\
26\end{array}$ & $\begin{array}{l}18 \\
17\end{array}$ & $<0.01$ \\
\hline \multicolumn{7}{|l|}{ Self-reported general health status } \\
\hline Smoking & $\begin{array}{l}\text { No } \\
\text { Yes }\end{array}$ & $\begin{array}{l}134 \\
70\end{array}$ & $\begin{array}{l}47 \\
27\end{array}$ & $\begin{array}{l}60 \\
35\end{array}$ & $\begin{array}{l}27 \\
8\end{array}$ & 0.29 \\
\hline Hypertension $^{\mathrm{a}}$ & $\begin{array}{l}\text { No } \\
\text { Yes }\end{array}$ & $\begin{array}{l}166 \\
38\end{array}$ & $\begin{array}{l}65 \\
9\end{array}$ & $\begin{array}{l}76 \\
19\end{array}$ & $\begin{array}{l}25 \\
10\end{array}$ & 0.11 \\
\hline Hypercholesterolemia $^{\mathrm{a}}$ & $\begin{array}{l}\text { No } \\
\text { Yes }\end{array}$ & $\begin{array}{l}165 \\
39\end{array}$ & $\begin{array}{l}67 \\
7\end{array}$ & $\begin{array}{l}73 \\
22\end{array}$ & $\begin{array}{l}25 \\
10\end{array}$ & 0.02 \\
\hline Family diabetes $^{\mathrm{a}}$ & $\begin{array}{l}\text { No } \\
\text { Yes }\end{array}$ & $\begin{array}{l}105 \\
99\end{array}$ & $\begin{array}{l}42 \\
32\end{array}$ & $\begin{array}{l}47 \\
48\end{array}$ & $\begin{array}{l}16 \\
19\end{array}$ & 0.49 \\
\hline $\mathrm{BMI}^{\mathrm{b}}$ & Continuous & $\begin{array}{l}26.5 \pm 4.5 \\
(N=203)\end{array}$ & $\begin{array}{l}25.0 \pm 4.1 \\
(N=73)\end{array}$ & $26.4 \pm 4.0(N=95)$ & $\begin{array}{l}29.8 \pm 4.9 \\
(N=35)\end{array}$ & $<0.01$ \\
\hline \multicolumn{7}{|l|}{ Periodontal health status } \\
\hline Severity of periodontitis & $\begin{array}{l}\text { Mild/Moderate } \\
\text { Severe }\end{array}$ & $\begin{array}{l}126 \\
78\end{array}$ & $\begin{array}{l}51 \\
23\end{array}$ & $\begin{array}{l}58 \\
37\end{array}$ & $\begin{array}{l}17 \\
18\end{array}$ & 0.12 \\
\hline Number of teeth & Continuous & $\begin{array}{l}26.0 \pm 3.6 \\
(N=204)\end{array}$ & $\begin{array}{l}26.6 \pm 3.1 \\
(N=74)\end{array}$ & $\begin{array}{l}25.8 \pm 3.6 \\
(N=95)\end{array}$ & $\begin{array}{l}25.4 \pm 4.5 \\
(N=35)\end{array}$ & 0.18 \\
\hline $\begin{array}{l}\text { Percentage of the number } \\
\text { of teeth with } \geq 50 \% \text { bone loss }(\%)^{\mathrm{c}}\end{array}$ & Continuous & $\begin{array}{l}16.3 \pm 18.1 \\
(N=194)\end{array}$ & $\begin{array}{r}12.5 \pm 13.9 \\
(N=70)\end{array}$ & $\begin{array}{r}17.4 \pm 19.9 \\
(N=91)\end{array}$ & $\begin{array}{r}21.3 \pm 19.4 \\
(N=33)\end{array}$ & 0.05 \\
\hline $\begin{array}{l}\text { Percentage of the number of teeth with } \\
\text { PPD } \geq 6 \mathrm{~mm}(\%)\end{array}$ & Continuous & $\begin{array}{l}36.4 \pm 29.7 \\
\quad(N=204)\end{array}$ & $\begin{array}{r}33.9 \pm 29.5 \\
(N=74)\end{array}$ & $\begin{array}{r}37.5 \pm 29.6 \\
(N=95)\end{array}$ & $\begin{array}{r}38.5 \pm 30.4 \\
(N=35)\end{array}$ & 0.66 \\
\hline $\begin{array}{l}\text { Percentage of the number of teeth } \\
\text { with mobility }(\%)^{\mathrm{d}}\end{array}$ & Continuous & $\begin{array}{r}14.9 \pm 19.3 \\
(N=202)\end{array}$ & $\begin{array}{r}11.1 \pm 14.7 \\
(N=72)\end{array}$ & $\begin{array}{r}15.5 \pm 19.7 \\
(N=95)\end{array}$ & $\begin{array}{r}21.2 \pm 24.8 \\
(N=35)\end{array}$ & 0.04 \\
\hline $\begin{array}{l}\text { Percentage of the number of teeth } \\
\text { with gingival recession }(\%)^{\mathrm{e}}\end{array}$ & Continuous & $\begin{array}{l}76.1 \pm 25.5 \\
(N=202)\end{array}$ & $\begin{array}{r}71.5 \pm 25.9 \\
(N=72)\end{array}$ & $\begin{array}{r}77.1 \pm 26.7 \\
(N=95)\end{array}$ & $\begin{array}{r}82.9 \pm 19.6 \\
(N=35)\end{array}$ & 0.09 \\
\hline Bleeding index ${ }^{\mathrm{f}}$ & Continuous & $\begin{array}{l}59.7 \pm 29.0 \\
(N=202)\end{array}$ & $\begin{array}{l}57.1 \pm 28.7 \\
(N=72)\end{array}$ & $\begin{array}{r}57.6 \pm 28.8 \\
(N=95)\end{array}$ & $\begin{array}{l}70.9 \pm 28.1 \\
(N=35)\end{array}$ & 0.04 \\
\hline Previous periodontal treatment $\mathrm{t}^{\mathrm{a}}$ & $\begin{array}{l}\text { No } \\
\text { Yes }\end{array}$ & $\begin{array}{l}109 \\
95\end{array}$ & 33 & $\begin{array}{l}51 \\
44\end{array}$ & $\begin{array}{l}25 \\
10\end{array}$ & 0.03 \\
\hline
\end{tabular}

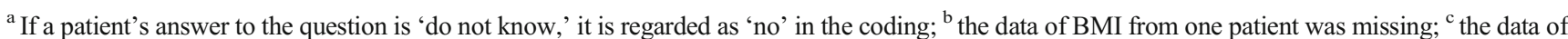
percentage of the number of teeth with $\geq 50 \%$ bone loss from 10 patients were missing; ${ }^{d}$ the data of percentage of the number of teeth with mobility from 2 patients were missing; ${ }^{e}$ the data of percentage of the number of teeth with gingival recession from 2 patients were missing; ${ }^{\mathrm{f}}$ the data of bleeding index from 2 patients were missing; ${ }^{\mathrm{g}}$ the $P$ values were produced from chi-square test for categorical predictors or from Kruskal-Wallis tests for continuous predictors; $D M$, diabetes mellitus; pre- $D M$, prediabetes; $B M I$, body mass index; $P P D$, probing pocket depth

\section{Discussion}

Based on the common and easily obtainable clinical variables, the present study derived a model for the screening of the diabetic status of patients with periodontitis. To the authors' knowledge, this is the first screening model for the diabetic status in patients with periodontitis in particular. There are already existing models for identification of DM in dental offices for the general dental patients [33-35], and for the prediction of the incident DM in the future in medical patients and general population [36-39]. In these previous models, patients' age, ethnicity, BMI, waist circumference, family history of DM, hypertension, and some biomarkers such as lipids level, uric acid level, and $\gamma$-glutamyltransferase level were the important predictors for DM. Some of these predictors, like age, European background, and BMI were also included in the present model. However, patients' self-reported family history of DM and hypertension were excluded from the present model, while several new periodontal related predictors, like percentage of the number of teeth with mobility and percentage of the number of teeth with gingival recession, were included in the present model. This may be because the target population of the present model is patients with periodontitis, so the effects of periodontal-related predictors on 
Table 2 Multivariate multinomial logistic regression analyses $(P \leq 0.25$ after backward selection) based on the diabetic status of patients with periodontitis, when no DM was regarded as the reference outcome category $(N=201)$

\begin{tabular}{|c|c|c|c|c|c|c|c|c|}
\hline \multirow[b]{2}{*}{ Predictors } & \multicolumn{4}{|l|}{ Pre-DM } & \multicolumn{4}{|l|}{$\mathrm{DM}$} \\
\hline & $\beta(\mathrm{SE})$ & Shrunken $\beta$ & OR (95\%CI) & $P$ value & $\beta(\mathrm{SE})$ & Shrunken $\beta$ & OR $(95 \% \mathrm{CI})$ & $P$ value \\
\hline Intercept & $-4.583(1.387)$ & -3.574 & & 0.001 & $-10.852(2.167)$ & -8.465 & & $<0.001$ \\
\hline Age & $0.056(0.018)$ & 0.044 & 1.058 (1.021 1.096) & 0.002 & $0.020(0.026)$ & 0.016 & $1.020\left(\begin{array}{lll}0.970 & 1.073)\end{array}\right.$ & 0.442 \\
\hline \multicolumn{9}{|l|}{ European background } \\
\hline European & Reference & & & & Reference & & & \\
\hline Non-European & $0.654(0.424)$ & 0.509 & $1.923(0.8384 .416)$ & 0.123 & $1.222(0.545)$ & 0.952 & $3.393(1.1659 .881)$ & 0.025 \\
\hline \multicolumn{9}{|l|}{ Hypercholesterolemia } \\
\hline No & Reference & & & & Reference & & & \\
\hline Yes & $0.627(0.489)$ & 0.488 & $1.872(0.7184 .880)$ & 0.200 & $0.993(0.624)$ & 0.774 & 2.699 (0.795 9.163) & 0.111 \\
\hline BMI & $0.056(0.042)$ & 0.044 & $1.058(0.9741 .149)$ & 0.183 & $0.239(0.057)$ & 0.186 & $1.270(1.137$ 1.419) & $<0.001$ \\
\hline $\begin{array}{l}\text { Percentage of the } \\
\text { number of teeth with } \\
\text { mobility }(\%)\end{array}$ & $0.011(0.010)$ & 0.009 & $1.011(0.9911 .032)$ & 0.287 & $0.021(0.012)$ & 0.016 & $1.021(0.9971 .047)$ & 0.091 \\
\hline $\begin{array}{l}\text { Percentage of the } \\
\text { number of teeth with } \\
\text { gingival recession }(\%)\end{array}$ & $0.000(0.007)$ & 0.000 & $1.000(0.9861 .014)$ & 0.967 & $0.014(0.011)$ & 0.011 & $1.015(0.9931 .036)$ & 0.180 \\
\hline \multicolumn{9}{|c|}{ Previous periodontal treatment } \\
\hline Yes & Reference & & & & Reference & & & \\
\hline No & $0.437(0.344)$ & 0.340 & $1.548(0.7893 .040)$ & 0.204 & $0.998(0.510)$ & 0.777 & $2.712(0.9987 .369)$ & 0.050 \\
\hline
\end{tabular}

$\beta$, coefficient; $S E$, standard error; $O R$, odds ratio; $C I$, confidence interval; $D M$, diabetes mellitus; pre-DM, prediabetes; $B M I$, body mass index

the outcome might be larger than other predictors, thus taking over the places in the model. In the present model, the biomarkers were not considered candidate predictors because laboratory tests are not routinely adopted for patients in dental clinics. Furthermore, the previous models targeted general population, medical patients, or general dental patients, but the present model particularly targeted patients with periodontitis. This is because much evidence has shown the strong bidirectional associations between DM and periodontal diseases. It is reasonable and necessary that the dental offices can be an important health-care location actively involved in screening for unidentified DM of periodontal patients. Besides, very few previous models have identified pre-DM separately from DM in dental settings. Pre-DM is a critical risk state that defines a high chance of developing diabetes. It is reported that for pre-diabetic individuals, lifestyle modification is the cornerstone of DM prevention with evidence of a 40-70\% relative risk reduction [40]. Early screening of preDM may prevent patients' diabetic status from being more severe and irreversible. So, early screening of pre-DM is as important as that of DM in clinical practice. That is why preDM and DM were treated as two separately outcome categories in the present model.

The risk of diabetes can be also identified by the National Institute for Health and Clinical Excellence (NICE) guidance tool in dental settings, based on patients' age, gender, ethnicity, family history of diabetes, hypertension, BMI, and the blood test at baseline [41]. The NICE guidance aimed to prevent or delay the progression of pre-DM and DM among highrisk groups, while the prediction model of the study aimed to identify the patients who have DM or pre-DM currently [42]. Therefore, the purposes of using these two screening tools are different. Besides, the NICE guidance was developed by the stakeholders' consensus, while the prediction model of the study was developed based on the mathematic approach. The individual predicted probability of getting DM cannot be calculated from the NICE guidance tool, and the predictive performance of the tool may not be quantitatively assessed.

The present model provides clinicians with information on patients' potential diabetic status. For periodontal clinicians, it is important to know the diabetic status of the patients with periodontitis. This is because, on one hand, the incidence and severity of periodontitis are influenced by the presence or absence of DM, and the degree to which DM is controlled by patients. On the other hand, if periodontal clinicians know that the patients have DM or pre-DM, they can refer the patients to physicians or give patients advice on the modification of lifestyles in time. For patients, it is also important to realize their own diabetic status so that patients can seek physicians' help in time. In clinical practice, the glycohemoglobin (HbAlc) test is considered an appropriate alternative to fasting plasma glucose for early screening of DM and pre-DM [43]. However, such test 


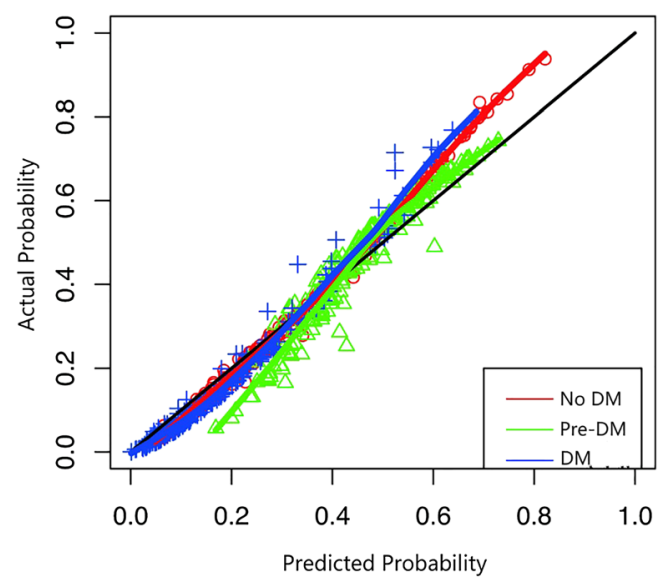

Fig. 1 Calibration plots of the multinomial regression model for predicted and actual probabilities of the three outcome categories in patients with periodontitis. The diagonal line is what would result if the predicted probability of the model was the same as the actual probability of the model so that the prediction is neither underestimated nor overestimated. The red curve is the calibration curve for no DM (number of patients with actual no DM is 71 , while that with predicted no $\mathrm{DM}$ is 58). The green curve is the calibration curve for pre-DM (number of patients with actual pre-DM is 95, while that with predicted pre-DM is 121). The blue curve is the calibration curve for DM (number of patients with actual DM is 35 , while number of patients with predicted $\mathrm{DM}$ is 22)

is bothersome for dental patients because it is invasive, time-consuming, expensive, and less accessible in dental settings. Therefore, the development of the present model can make the screening of DM and pre-DM in dental settings more user-friendly by making it non-invasive, faster, cheaper, and accessible for every patient. This

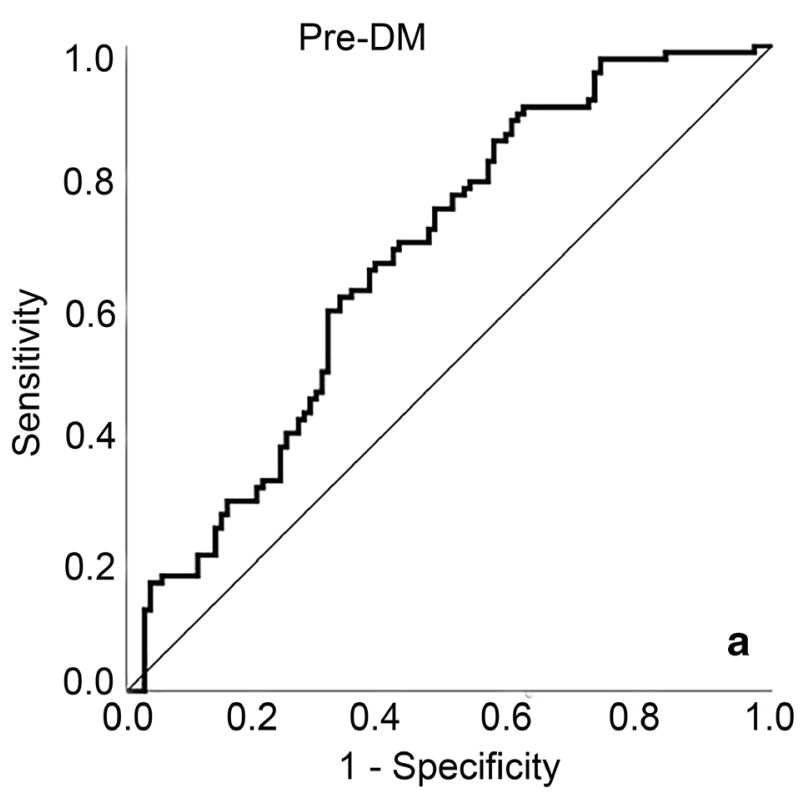

Fig. 2 Discrimination ability of the multinomial regression model for screening of DM and pre-DM in patients with periodontitis. $\mathbf{a}$ is the ROC areas of pre-DM vs no DM and DM with an AUC of 0.67 can help in reducing patients' burden for the diagnosis of DM to a large extent.

Both the discrimination and calibration of the model were acceptable in general, which indicated that the performance of the model may be suitable in clinical practice. However, clinicians need to be aware that a false positive prediction can lead to unnecessarily extended examinations or treatments for $\mathrm{DM}$ or pre-DM in patients with periodontitis, thereby adding to the financial and psychological burdens. Similarly, a false negative prediction can lead to undertreatment for diabetic or prediabetic conditions, which may result in less desirable health outcomes. Based on the present model, the risk of a false positive prediction of DM and pre-DM was 0.04 and 0.25 , respectively, while the risk of a false negative prediction of DM and pre-DM was 0.11 and 0.12 , respectively. This indicates a high risk of false positive prediction of pre-DM, thereby suggesting that $25 \%$ of the patients with periodontitis may have a false positive prediction of pre-DM. However, the negative consequence of the false positives for the patients does not seem to be very severe. In addition, this model can be used as a chairside screening tool, allowing further confirmation of the (pre)DM based on physicians' diagnosis. Therefore, false positive prediction is not likely to affect patients' health outcomes, indicating the risk of false positives and false negatives as acceptable by this model.

In the present study, the added predictive values of the model for ruling in DM and pre-DM were 0.42 and 0.11 , respectively, while those for ruling it out were 0.05 and 0.17 , respectively. That indicates that if a patient with periodontitis is predicted to have DM or pre-DM based on the

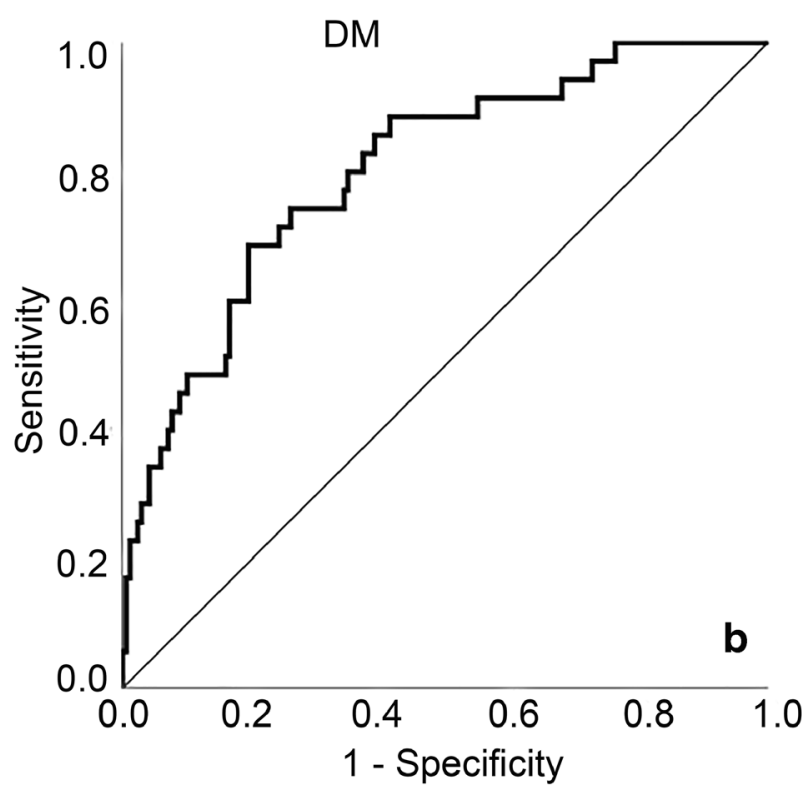

(95\%CI, 0.60, 0.75) and $\mathbf{b}$ is the ROC areas of DM vs no DM and preDM with an AUC of 0.80 (95\%CI, 0.72, 0.88) 
Table 3 Clinical values of the model $(N=201)$

\begin{tabular}{|c|c|c|c|c|c|c|c|}
\hline Outcome category & $\begin{array}{l}\text { Prevalence } \\
(95 \% \text { CI })\end{array}$ & Sensitivity $(95 \% \mathrm{CI})$ & $\begin{array}{l}\text { Specificity } \\
(95 \% \text { CI })\end{array}$ & $\begin{array}{l}\text { PPV } \\
(95 \% \mathrm{CI})\end{array}$ & $\begin{array}{l}\text { NPV } \\
(95 \% \text { CI) }\end{array}$ & $\begin{array}{l}\text { Added value for ruling } \\
\text { in the risk of (pre)DM } \\
(95 \% \mathrm{CI})\end{array}$ & $\begin{array}{l}\text { Added value for ruling } \\
\text { out the risk of (pre)DM } \\
(95 \% \mathrm{CI})\end{array}$ \\
\hline DM & $\begin{array}{l}0.17 \\
\left(\begin{array}{ll}0.13 & 0.23\end{array}\right)\end{array}$ & $\begin{array}{l}0.37 \\
(0.220 .54)\end{array}$ & $\begin{array}{l}0.95 \\
\left(\begin{array}{lll}0.90 & 0.97\end{array}\right)\end{array}$ & $\begin{array}{l}0.59 \\
\left(\begin{array}{lll}0.38 & 0.78\end{array}\right)\end{array}$ & $\begin{array}{l}0.88 \\
\left(\begin{array}{lll}0.82 & 0.92\end{array}\right)\end{array}$ & $\begin{array}{l}0.42 \\
(0.200 .63)\end{array}$ & $\begin{array}{l}0.05 \\
\left(\begin{array}{ll}-0.02 & 0.12\end{array}\right)\end{array}$ \\
\hline Pre-DM & $\begin{array}{l}0.47 \\
\left(\begin{array}{lll}0.40 & 0.54\end{array}\right)\end{array}$ & $\begin{array}{l}0.75 \\
\left(\begin{array}{lll}0.65 & 0.83\end{array}\right)\end{array}$ & $\begin{array}{l}0.53 \\
\left(\begin{array}{ll}0.43 & 0.62\end{array}\right)\end{array}$ & $\begin{array}{l}0.59 \\
\left(\begin{array}{lll}0.50 & 0.67\end{array}\right)\end{array}$ & 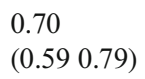 & $\begin{array}{l}0.11 \\
\left(\begin{array}{lll}0.00 & 0.22\end{array}\right)\end{array}$ & $\begin{array}{l}0.17 \\
(0.050 .29)\end{array}$ \\
\hline
\end{tabular}

$C I$, confidence interval; $P P V$, positive predictive value; $N P V$, negative predictive value; $D M$, diabetes mellitus; $p r e-D M$, prediabetes

model, the posterior risk of having DM or pre-DM of this patient can be increased by 0.42 and 0.11 compared with the prevalences of DM and pre-DM in patients with periodontitis. Similarly, if a patient with periodontitis is predicted not to have DM (i.e., the patient is predicted to have "no DM" or "pre-DM") or pre-DM (i.e., the patient is predicted to have "no DM" or "DM") based on the model, the posterior risk of not having DM or pre-DM of this patient can be increased by 0.05 and 0.17 , respectively, when compared with the complement of the prevalences of DM or pre-DM in patients with periodontitis. It should be noted that the added value of the model for ruling out DM is only 0.05 , which seems to add only little benefit. However, the prevalence of DM in patients with periodontitis is only $17 \%$. This means that the majority $(83 \%)$ of the patients do not have DM. Therefore, there is only little space for the model to add more value to the complement of the prevalence of DM. In this case, $5 \%$ of the added value can be acceptable. Therefore, the added values of the model for ruling in and out DM and pre-DM are considerable, so it adds to accurate prediction of DM and pre-DM.

Sample size is typically a severe problem for multinomial regression models because one or more of the outcome categories often have very low prevalence [32]. For the multinomial model with three outcome categories, the events per variable (EPV) are advised to be larger than 20 [28]. Insufficient sample size may underestimate the importance of the potential predictors and tends to make the clinically important predictors insignificant. Therefore, insufficient sample size may negatively impact the robustness of the performance of the
Table 4 Score chart of the multinomial model for prediction of diabetic status of patients with periodontitis $(N=201)$

\begin{tabular}{lll}
\hline & Pre-DM & DM \\
\cline { 2 - 3 } Predictors & Score & Score \\
\hline Age & $5 *$ age & $2 *$ age \\
European background & & \\
$\quad$ European & 0 & 0 \\
Non-European & 57 & 106 \\
Hypercholesterolemia & & 0 \\
No & 0 & 86 \\
Yes & 54 & $21 * \mathrm{BMI}$ \\
BMI & $5 * \mathrm{BMI}$ & $200 * \%$ \\
Percentage of the number of teeth with mobility $(\%)$ & $100 * \%$ & $100 * \%$ \\
Percentage of the number of teeth with gingival recession $(\%)$ & $0 * \%$ & 0 \\
Previous periodontal treatment & & 86 \\
$\quad$ Yes & 0 & \\
No & 38 & \\
Sum score & & \\
\hline
\end{tabular}

$D M$, diabetes mellitus; pre- $D M$, prediabetes; $B M I$, body mass index

The algorithms for the calculation of an individual's sum scores for pre-DM and DM were emerged from the modeling:

Sum score for pre-DM $=5 *$ Age $+57 *$ non-European $+54 *$ presence of hypercholesterolemia $+5 * B M I+100 *$ percentage of the number of teeth with mobility $+38 *$ no previous periodontal treatment

Sum score for DM=2*age $+106 *$ non-European $+86 *$ presence of hypercholesterolemia $+21 * B M I+200 *$ percentage of the number of teeth with mobility $+100^{*}$ percentage of the number of teeth with gingival recession + $86^{*}$ no previous periodontal treatment 


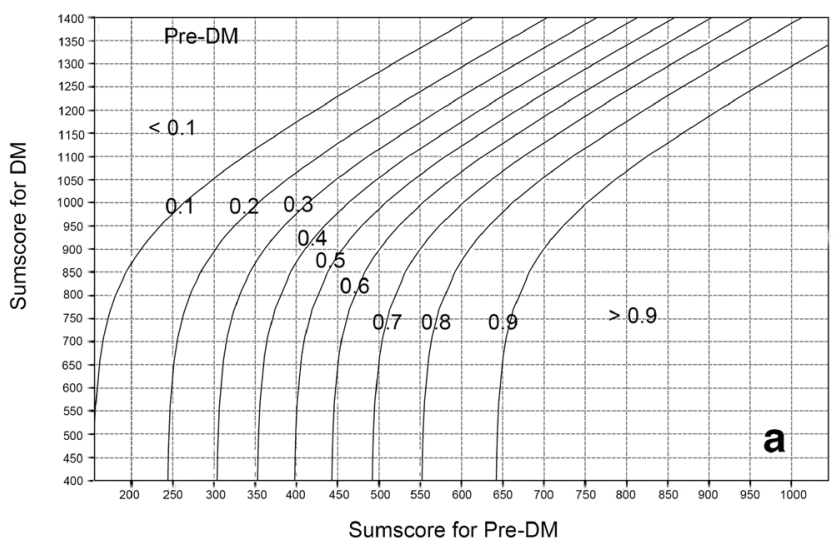

Fig. 3 Line charts of the multinomial regression model for determining the predicted probability of a pre-DM and $\mathbf{b}$ DM. The cross point of a vertical line drawn from the $\mathrm{x}$-axis and a horizontal line drawn from the $\mathrm{y}$ axis shows the corresponding predicted probability of the outcome

model [44]. However, the present study did not meet the criterion because of the small sample size, which was a limitation of the study. That is why, in the present study, a less stringent threshold of $P$ value of 0.25 was used in both the bivariate tests and multivariate regression analyses in the selection and exclusion of potential predictors. This could avoid false negative findings in both modeling stages to a large extent, especially when the sample size is small $[27+]$. Another limitation of the study is that the discrimination of the model in terms of pre-DM is not satisfactory based on the current predictors. This may be because pre-DM is an intermediate status between DM and no DM, and the distinction between pre-DM and $\mathrm{DM}$ and between pre$\mathrm{DM}$ and no DM was not as large as that between DM and no DM. So, it is more difficult for the model to discriminate the patients with pre-DM from the patients with DM or with no DM. Therefore, researchers are suggested to look for and test other predictors in the future, which are relevant to the occurrence and progression of pre-DM, to update and improve the performance of the current model. Another limitation is the clinical feasibility of some predictors of the model. For example, complete measurements of tooth mobility and full mouth gingiva recession may not be routinely collected in every dental office. The model may add extra workload to clinicians to collect those predictors for each individual patient. Besides, hypercholesterolemia and BMI in the model are patients self-reported. The validity of these self-reported predictors may be questionable. For example, hypercholesterolemia may be underestimated by patients' self-reporting [45], and this may bias the predictive performance of the model.

Future researchers are suggested to externally validate the present model in other populations and to assess the added values of other relevantly important predictors such as waist

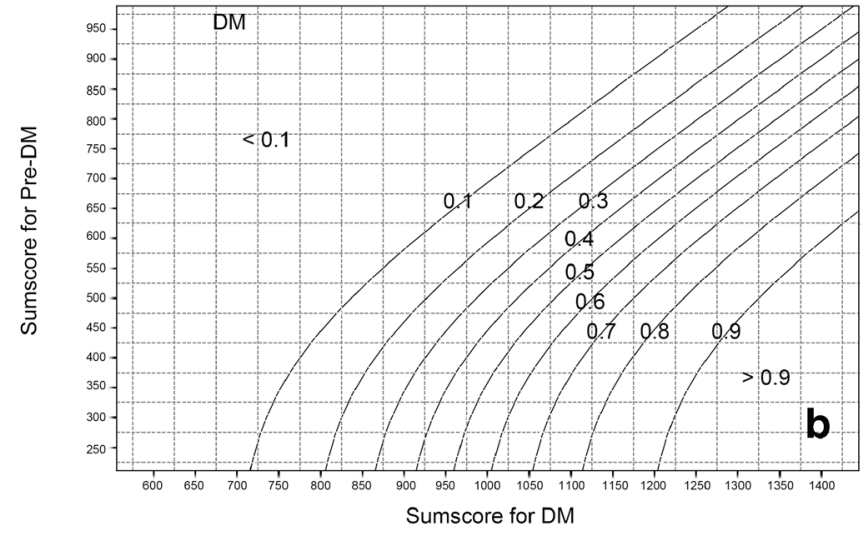

category. The corresponding predicted probability of no DM can be calculated by $100 \%$ minus the predicted probability of pre-DM minus the predicted probability of DM

circumference and biomarkers including lipids level, uric acid level, and $\gamma$-glutamyltransferase level to the performance of the model. Besides, it is recommended to explore more dental predictors for DM and pre-DM as they can be more easily collected by dentists at the chairside.

\section{Conclusions}

Potential predictors in patient profiles for screening of DM and pre-DM in patients with periodontitis were identified. The multinomial regression model for screening of DM and pre-DM was developed and internally validated. The calibration and discrimination of the model were acceptable. The added predictive values were considerable for both ruling in and ruling out DM and pre-DM in decision-making. The model can be used as a reliable screening tool for DM and pre-DM in patients with periodontitis in dental settings.

Authors' contributions All the authors contributed to the study conception and design. Naichuan Su, Wijnand J. Teeuw, and Madeline X.F. Kosho contributed to the data acquisition. Naichuan Su, Bruno G. Loos, and Geert J.M.G. van der Heijden contributed to the data analysis and interpretation. The first draft of the manuscript was written by Naichuan $\mathrm{Su}$, and all authors commented on previous versions of the manuscript. All authors read and approved the final manuscript.

\section{Compliance with ethical standards}

Conflict of interest The authors declare that they have no conflict of interest.

Ethical approval The study has been approved by the Medical Ethics Review Committee of the VU University Medical Center Amsterdam (VUmc) (2013.343). All procedures performed in the study involving human participants were in accordance with the ethical standards of the Medical Ethics Review Committee of VUmc (2013.343) and with the 1964 Helsinki Declaration and its later amendments or comparable ethical standards. 
Informed consent Informed consent was obtained from all individual participants included in the study.

Open Access This article is licensed under a Creative Commons Attribution 4.0 International License, which permits use, sharing, adaptation, distribution and reproduction in any medium or format, as long as you give appropriate credit to the original author(s) and the source, provide a link to the Creative Commons licence, and indicate if changes were made. The images or other third party material in this article are included in the article's Creative Commons licence, unless indicated otherwise in a credit line to the material. If material is not included in the article's Creative Commons licence and your intended use is not permitted by statutory regulation or exceeds the permitted use, you will need to obtain permission directly from the copyright holder. To view a copy of this licence, visit http://creativecommons.org/licenses/by/4.0/.

\section{References}

1. Preshaw PM, Alba AL, Herrera D, Jepsen S, Konstantinidis A, Makrilakis K, Taylor R (2012) Periodontitis and diabetes: a twoway relationship. Diebetologia 55:21-31. https://oi.org/10.1007/ s00125-011-2342-y

2. Vos T, Flaxman AD, Naghavi M, Lozano R, Michaud C, Ezzati M, Shibuya K, Salomon JA, Abdalla S, Aboyans V, Abraham J, Ackerman I, Aggarwal R, Ahn SY, Ali MK, AlMazroa MA, Alvarado M, Anderson HR, Anderson LM, Andrews KG, Atkinson C, Baddour LM, Bahalim AN, Barker-Collo S, Barrero LH, Bartels DH, Basáñez MG, Baxter A, Bell ML, Benjamin EJ, Bennett D, Bernabé E, Bhalla K, Bhandari B, Bikbov B, Abdulhak AB, Birbeck G, Black JA, Blencowe H, Blore JD, Blyth F, Bolliger I, Bonaventure A, Boufous S, Bourne R, Boussinesq M, Braithwaite T, Brayne C, Bridgett L, Brooker S, Brooks P, Brugha TS, Bryan-Hancock C, Bucello C, Buchbinder R, Buckle G, Budke CM, Burch M, Burney P, Burstein R, Calabria B, Campbell B, Canter CE, Carabin H, Carapetis J, Carmona L, Cella C, Charlson F, Chen H, Cheng ATA, Chou D, Chugh SS, Coffeng LE, Colan SD, Colquhoun S, Colson KE, Condon J, Connor MD, Cooper LT, Corriere M, Cortinovis M, de Vaccaro KC, Couser W, Cowie BC, Criqui MH, Cross M, Dabhadkar KC, Dahiya M, Dahodwala N, Damsere-Derry J, Danaei G, Davis A, de Leo D, Degenhardt L, Dellavalle R, Delossantos A, Denenberg J, Derrett S, Des Jarlais DC, Dharmaratne SD, Dherani M, DiazTorne C, Dolk H, Dorsey ER, Driscoll T, Duber H, Ebel B, Edmond K, Elbaz A, Ali SE, Erskine H, Erwin PJ, Espindola P, Ewoigbokhan SE, Farzadfar F, Feigin V, Felson DT, Ferrari A, Ferri CP, Fèvre EM, Finucane MM, Flaxman S, Flood L, Foreman K, Forouzanfar MH, Fowkes FGR, Franklin R, Fransen M, Freeman MK, Gabbe BJ, Gabriel SE, Gakidou E, Ganatra HA, Garcia B, Gaspari F, Gillum RF, Gmel G, Gosselin R, Grainger R, Groeger J, Guillemin F, Gunnell D, Gupta R, Haagsma J, Hagan H, Halasa YA, Hall W, Haring D, Haro JM, Harrison JE, Havmoeller R, Hay RJ, Higashi H, Hill C, Hoen B, Hoffman H, Hotez PJ, Hoy D, Huang JJ, Ibeanusi SE, Jacobsen KH, James SL, Jarvis D, Jasrasaria R, Jayaraman S, Johns N, Jonas JB, Karthikeyan G, Kassebaum N, Kawakami N, Keren A, Khoo JP, King CH, Knowlton LM, Kobusingye O, Koranteng A, Krishnamurthi R, Lalloo R, Laslett LL, Lathlean T, Leasher JL, Lee YY, Leigh J, Lim SS, Limb E, Lin JK, Lipnick M, Lipshultz SE, Liu W, Loane M, Ohno SL, Lyons R, Ma J, Mabweijano J, MacIntyre MF, Malekzadeh R, Mallinger L, Manivannan S, Marcenes W, March L, Margolis DJ, Marks GB, Marks R, Matsumori A, Matzopoulos R, Mayosi BM, McAnulty JH, McDermott MM, McGill N, McGrath J, Medina-Mora ME, Meltzer M, Memish ZA, Mensah
GA, Merriman TR, Meyer AC, Miglioli V, Miller M, Miller TR, Mitchell PB, Mocumbi AO, Moffitt TE, Mokdad AA, Monasta L, Montico M, Moradi-Lakeh M, Moran A, Morawska L, Mori R, Murdoch ME, Mwaniki MK, Naidoo K, Nair MN, Naldi L, Narayan KMV, Nelson PK, Nelson RG, Nevitt MC, Newton CR, Nolte S, Norman P, Norman R, O'Donnell M, O'Hanlon S, Olives C, Omer SB, Ortblad K, Osborne R, Ozgediz D, Page A, Pahari B, Pandian JD, Rivero AP, Patten SB, Pearce N, Padilla RP, PerezRuiz F, Perico N, Pesudovs K, Phillips D, Phillips MR, Pierce K, Pion S, Polanczyk GV, Polinder S, Pope CA III, Popova S, Porrini E, Pourmalek F, Prince M, Pullan RL, Ramaiah KD, Ranganathan D, Razavi H, Regan M, Rehm JT, Rein DB, Remuzzi G, Richardson K, Rivara FP, Roberts T, Robinson C, de Leòn FR, Ronfani L, Room R, Rosenfeld LC, Rushton L, Sacco RL, Saha S, Sampson U, Sanchez-Riera L, Sanman E, Schwebel DC, Scott JG, Segui-Gomez M, Shahraz S, Shepard DS, Shin H, Shivakoti R, Silberberg D, Singh D, Singh GM, Singh JA, Singleton J, Sleet DA, Sliwa K, Smith E, Smith JL, Stapelberg NJC, Steer A, Steiner T, Stolk WA, Stovner LJ, Sudfeld C, Syed S, Tamburlini G, Tavakkoli M, Taylor HR, Taylor JA, Taylor WJ, Thomas B, Thomson WM, Thurston GD, Tleyjeh IM, Tonelli M, Towbin JA, Truelsen T, Tsilimbaris MK, Ubeda C, Undurraga EA, van der Werf MJ, van Os J, Vavilala MS, Venketasubramanian N, Wang M, Wang W, Watt K, Weatherall DJ, Weinstock MA, Weintraub R, Weisskopf MG, Weissman MM, White RA, Whiteford H, Wiersma ST, Wilkinson JD, Williams HC, Williams SRM, Witt E, Wolfe F, Woolf AD, Wulf S, Yeh PH, Zaidi AKM, Zheng ZJ, Zonies D, Lopez AD, Murray CJL (2012) Years lived with disability (YLDs) for 1160 sequelae of 289 diseases and injuries 1990-2010: a systematic analysis for the global burden of disease study 2010. Lancet 380:2163-2196. https://doi.org/10.1016/S0140-6736(12)61729-2

3. Blair M (2016) Diabetes mellitus review. Urol Nurs 36:27-36

4. Guariguata L, Whiting DR, Hambleton I, Beagley J, Linnenkamp U, Shaw JE (2014) Global estimates of diabetes prevalence for 2013 and projections for 2035. Diabetes Res Clin Pract 103:137149. https://doi.org/10.1016/j.diabres.2013.11.002

5. Polak D, Shapira L (2018) An update on the evidence for pathogenic mechanisms that may link periodontitis and diabetes. J Clin Periodontol 45:150-166. https://doi.org/10.1111/jcpe.12803

6. Chiu SY, Lai H, Yen AM, Fann JC, Chen LS, Chen HH (2015) Temporal sequence of the bidirectional relationship between hyperglycemia and periodontal disease: a community-based study of 5 , 885 Taiwanese aged 35-44 years (KCIS no. 32). Acta Diabetol 52: 123-131. https://doi.org/10.1007/s00592-014-0612-0

7. Salvi GE, Carollo-Bittel B, Lang NP (2008) Effects of diabetes mellitus on periodontal and peri-implant conditions: update on associations and risks. J Clin Periodontol 35:398-409. https://doi.org/ 10.1111/j.1600-051X.2008.01282.x

8. Verhulst MJL, Loos BG, Gerdes VEA, Teeuw W (2019) Evaluating all potential oral complications of diabetes mellitus. Front Endocrinol (Lausanne) 10:56. https://doi.org/10.3389/ fendo.2019.00056

9. Daniel R, Gokulanathan S, Shanmugasundaram N, Lakshmigandhan M, Kavin T (2012) Diabetes and periodontal disease. J Pharm Bioallied Sci 4:S280-S282. https://doi.org/10. 4103/0975-7406.100251

10. Nascimento GG, Leite FRM, Vestergaard P, Scheutz F, López R (2018) Does diabetes increase the risk of periodontitis? A systematic review and meta-regression analysis of longitudinal prospective studies. Acta Diabetol 55:653-667. https://doi.org/10.1007/ s00592-018-1120-4

11. Kowall B, Holtfreter B, Völzke H, Schipf S, Mundt T, Rathmann W, Kocher T (2015) Pre-diabetes and well-controlled diabetes are not associated with periodontal disease: the SHIP trend study. J Clin Periodontol 42:422-430. https://doi.org/10.1111/jcpe.12391 
12. Montero E, Carasol M, Fernández-Meseguer A, Calvo-Bonacho E, García-Margallo MT, Sanz M, Herrera D (2019) Prediabetes and diabetes prevalence in the workers' oral health study. Clin Oral Investig 23:4233-4241. https://doi.org/10.1007/s00784-01902875-3

13. Maboudi A, Akha O, Heidari M, Mohammadpour RA, Gheblenama P, Shiva A (2019) Relation between periodontitis and prediabetic condition. J Dent (Shiraz) 20:83-89

14. Demmer RT, Jacobs DR Jr, Singh R, Zuk A, Rosenbaum M, Papapanou PN, Desvarieux M (2015) Periodontal bacteria and prediabetes prevalence in ORIGINS: the oral infections, glucose intolerance, and insulin resistance study. J Dent Res 94:201S-211S. https://doi.org/10.1177/0022034515590369

15. Yonel Z, Batt J, Jane R, Cerullo E, Gray LJ, Dietrich T, Chapple I (2020) The role of the oral healthcare team in identification of type 2 diabetes mellitus: a systematic review. Curr Oral Health Rep 7: 87-97

16. Rees TD (2000) Periodontal management of the patient with diabetes mellitus. Periodontol 2000(23):63-72. https://doi.org/10. 1034/j.1600-0757.2000.2230105.x

17. Santos CM, Lira-Junior R, Fischer RG, Santos AP, Oliveira BH (2015) Systemic antibiotics in periodontal treatment of diabetic patients: a systematic review. PLoS One 10:e0145262. https://doi. org/10.1371/journal.pone.0145262

18. Herman WH, Ye W, Griffin SJ, Simmons RK, Davies MJ, Khunti K, Rutten GEHM, Sandbaek A, Lauritzen T, Borch-Johnsen K, Brown MB, Wareham NJ (2015) Early detection and treatment of type 2 diabetes reduce cardiovascular morbidity and mortality: a simulation of the results of the Anglo-Danish-Dutch study of intensive treatment in people with screen-detected diabetes in primary care (ADDITION-Europe). Diabetes Care 38:1449-1455. https:// doi.org/10.2337/dc14-2459

19. Stewart JE, Wager KA, Friedlander AH, Zadeh HH (2001) The effect of periodontal treatment on glycemic control in patients with type 2 diabetes mellitus. J Clin Periodontol 28:306-310. https://doi. org/10.1034/j.1600-051x.2001.028004306.x

20. Kaur PK, Narula SC, Rajput R, Sharma RK, Tewari S (2015) Periodontal and glycemic effects of nonsurgical periodontal therapy in patients with type 2 diabetes stratified by baseline HbAlc. J Oral Sci 57:201-211. https://doi.org/10.2334/josnusd.57.201

21. Kocher T, Holtfreter B, Petersmann A, Eickholz P, Hoffmann T, Kaner D, Kim TS, Meyle J, Schlagenhauf U, Doering S, Gravemeier M, Prior K, Rathmann W, Harks I, Ehmke B, Koch $\mathrm{R}$ (2019) Effect of periodontal treatment on HbA1c among patients with prediabetes. J Dent Res 98:171-179. https://doi.org/10.1177/ 0022034518804185

22. Teeuw WJ, Kosho MX, Poland DC, Gerdes VE, Loos BG (2017) Periodontitis as a possible early sign of diabetes mellitus. BMJ Open Diabetes Res Care 5:e00326. https://doi.org/10.1136/ bmjdrc-2016-000326

23. Kim SM, Lee JS, Lee J, Na JK, Han JH, Yoon DK, Baik SH, Choi DS, Choi KM (2006) Prevalence of diabetes and impaired fasting glucose in Korea: Korean National Health and nutrition survey 2001. Diabetes Care 29:226-231. https://doi.org/10.2337/diacare. 29.02.06.dc05-0481

24. Lyu YS, Kim SY, Bae HY, Kim JH (2019) Prevalence and risk factors for undiagnosed glucose intolerance status in apparently healthy young adults aged $<40$ years: the Korean National Health and nutrition examination survey 2014-2017. Int J Environ Res Public Health 16:E2393. https://doi.org/10.3390/ijerph16132393

25. Barasch A, Safford MM, Qvist V, Palmore R, Gesko D, Gilbert GH Dental Practice-Based Research Network Collaborative Group (2012) Random blood glucose testing in dental practice: a community-based feasibility study from The Dental PracticeBased Research Network. J Am Dent Assoc 143:262-269. https:// doi.org/10.14219/jada.archive.2012.0151
26. American Diabetes Association (2015) Classification and diagnosis of diabetes. Diabetes Care 38:S8-S16. https://doi.org/10.2337/ dc15-S005

27. Bagherzadeh-Khiabani F, Ramezankhani A, Azizi F, Hadaegh F, Steyerberg EW, Khalili D (2016) A tutorial on variable selection for clinical prediction models: feature selection methods in data mining could improve the results. J Clin Epidemiol 71:76-85. https://doi. org/10.1016/j.jclinepi.2015.10.002

28. Biesheuvel CJ, Vergouwe Y, Steyerberg EW, Grobbee DE, Moons KG (2008) Polytomous logistic regression analysis could be applied more often in diagnostic research. J Clin Epidemiol 61:125134. https://doi.org/10.1016/j.jclinepi.2007.03.002

29. Steyerberg EW (2009) Validation of prediction models. In: Steyerberg EW (ed) Clinical prediction models: a practice approach to development, validation, and updating. Springer Science \& Business Media, Berlin, pp 299-311

30. Steyerberg EW, Vickers AJ, Cook NR, Gerds T, Gonen M, Obuchowski N, Pencina MJ, Kattan MW (2010) Assessing the performance of prediction models: a framework for traditional and novel measures. Epidemiology 21:128-138. https://doi.org/ 10.1097/EDE.0b013e3181c30fb2

31. Lee EC, Park SJ, Han SS, Shim JR, Park HM, Lee SD, Kim SH (2018) Risk prediction of post-hepatectomy liver failure in patients with perihilar cholangiocarcinoma. J Gastroenterol Hepatol 33: 958-965. https://doi.org/10.1111/jgh.13966

32. Van Calster B, Van Belle V, Vergouwe Y, Timmerman D, Van Huffel S, Steyerberg EW (2012) Extending the c-statistic to nominal polytomous outcomes: the polytomous discrimination index. Stat Med 31:2610-2626. https://doi.org/10.1002/sim.5321

33. Li S, Williams PL, Douglass CW (2011) Development of a clinical guideline to predict undiagnosed diabetes in dental patients. J Am Dent Assoc 142:28-37. https://doi.org/10.14219/jada.archive. 2011.0025

34. Borrell LN, Kunzel C, Lamster I, Lalla E (2007) Diabetes in the dental office: using NHANES II to estimate the probability of undiagnosed disease. J Periodontal Res 42:559-565. https://doi.org/ 10.1111/j.1600-0765.2007.00983.x

35. Holm NC, Belstrøm D, Østergaard JA, Schou S, Holmstrup P, Grauballe MB (2016) Identification of individuals with undiagnosed diabetes and pre-diabetes in a Danish cohort attending dental treatment. J Periodontol 87:395-402. https://doi.org/10.1902/jop. 2016.150266

36. Abbasi A, Peelen LM, Corpeleijn E, van der Schouw YT, Stolk RP, Spijkerman AM et al (2012) Prediction models for risk of developing type 2 diabetes: systematic literature search and independent external validation study. BMJ 345:e5900. https://doi.org/10. 1136/bmj.e5900

37. van Leeuwen $\mathrm{M}$, Opmeer BC, Zweers EJ, van Ballegooie E, ter Brugge HG, de Valk HW, Visser GH, Mol BW (2010) Estimating the risk of gestational diabetes mellitus: a clinical prediction model based on patient characteristics and medical history. BJOG 117:6975. https://doi.org/10.1111/j.1471-0528.2009.02425.x

38. Chen L, Magliano DJ, Balkau B, Colagiuri S, Zimmet PZ, Tonkin AM, Mitchell P, Phillips PJ, Shaw JE (2010) AUSDRISK: an Australian type 2 diabetes risk assessment tool based on demographic, lifestyle and simple anthropometric measures. Med J Aust 192:197-202

39. Rosella LC, Manuel DG, Burchill C, Stukel TA, PHIAT-DM team (2011) A population-based risk algorithm for the development of diabetes: development and validation of the diabetes population risk tool (DPoRT). J Epidemiol Community Health 65:613-620. https:// doi.org/10.1136/jech.2009.102244

40. Tabák AG, Herder C, Rathmann W, Brunner EJ, Kivimäki M (2012) Prediabetes: a high-risk state for developing diabetes. Lancet 379:2279-2290. https://doi.org/10.1016/S0140-6736(12) 60283-9 
41. Wright D, Muirhead V, Weston-Price S, Fortune F (2014) Type 2 diabetes risk screening in dental practice settings: a pilot study. $\mathrm{Br}$ Dent J 216:E15. https://doi.org/10.1038/sj.bdj.2014.250

42. National Institute for Clinical Care and Excellence (2012) Preventing type 2 diabetes: risk identification and interventions for individuals at high risk. NICE public health guidance 38, Manchester

43. Lim WY, Ma S, Heng D, Tai ES, Khoo CM, Loh TP (2018) Screening for diabetes with $\mathrm{HbAlc}$ : test performance of HbA1c compared to fasting plasma glucose among Chinese, Malay and Indian community residents in Singapore. Sci Rep 8:12419. https://doi.org/10.1038/s41598-018-29998-Z

44. van Smeden M, Moons KG, de Groot JA, Collins GS, Altman DG, Eijkemans MJ, Reitsma JB (2019) Sample size for binary logistic prediction models: beyond events per variable criteria. Stat Methods Med Res 28:2455-2474. https://doi.org/10.1177/ 0962280218784726

45. Tolonen H, Koponen P, Mindell JS, Männistö S, Giampaoli S, Dias $\mathrm{CM}$ et al (2014) Under-estimation of obesity, hypertension and high cholesterol by self-reported data: comparison of self-reported information and objective from health examination surveys. Eur J Pub Health 24:941-948. https://doi.org/10.1093/eurpub/cku074

Publisher's note Springer Nature remains neutral with regard to jurisdictional claims in published maps and institutional affiliations. 